\title{
Ropivacaine for Unilateral Spinal Anesthesia; Hyperbaric or Hypobaric?
}

\author{
Mehmet Cantürk ${ }^{1}$, Oya Kılcı ${ }^{1}$, Dilşen Ornek ${ }^{1}$, Levent Ozdogan ${ }^{1}$, Yasar Pala ${ }^{1}$, Ozlem Sen ${ }^{1}$, Bayazit Dikmen ${ }^{1}$
}

Summary: Cantürk M, Kılcı O, Ornek D, Ozdogan L, Pala Y, Sem O, Dikmen B - Ropivacaine for Unilateral Spinal Anesthesia; Hyperbaric or Hypobaric?

Background and objectives: The aim of this study was to compare the unilaterality of subarachnoid block achieved with hyperbaric and hypobaric ropivacaine.

Methods: The prospective, randomized trial was conducted in an orthopedics surgical suite. In all, 60 ASA I-III patients scheduled for elective total knee arthroplasty were included in the study. Group Hypo $(\mathrm{n}=30)$ received $11.25 \mathrm{mg}$ of ropivacaine $\left(7.5 \mathrm{mg} \cdot \mathrm{mL}^{-1}\right)+2 \mathrm{~mL}$ of distilled water $($ density at room temperature was 0.997$)$ and group Hyper $(n=30)$ received $11.25 \mathrm{mg}$ of ropivacaine $\left(7.5 \mathrm{mg} \cdot \mathrm{mL}^{-1}\right)+2 \mathrm{~mL}\left(5 \mathrm{mg} \cdot \mathrm{mL}^{-1}\right)$ of dextrose $($ density at room temperature was 1,015). Patients in the hyperbaric group were positioned with the operated side down and in the $15^{\circ}$ Fowler position, versus those in the hypobaric group with the operated side facing up and in the $15^{\circ}$ Trendelenburg position. Combined spinal epidural anesthesia was performed midline at the $\mathrm{L}_{3-4}$ lumbar interspace. Hemodynamic and spinal block parameters, regression time, success of unilateral spinal anesthesia, patient comfort, surgical comfort, surgeon comfort, first analgesic requirement time, and adverse effects were assessed.

Results: Time to reach the T10 dermatome level on the operated side was shorter in group Hyper (612.00 $\pm 163.29 \mathrm{~s})$ than in group Hypo $(763.63 \pm 208.35 \mathrm{~s})(\mathrm{p}<0.05)$. Time to 2 -segment regression of the sensory block level on both the operated and non-operated sides was shorter in group Hypo than in group Hyper.

Conclusion: Both hyperbaric and hypobaric ropivacaine $(11.25 \mathrm{mg})$ provided adequate and dependable anesthesia for total knee replacement surgery, with a high level of patient and surgeon comfort. Hypobaric local anesthetic solutions provide a high level of unilateral anesthesia, with rapid recovery of both sensory and motor block, and therefore may be preferable in outpatient settings.

Keywords: Anesthesia, Epidural; Anesthesia, Spinal; Anesthetics, Local/ropivacaine; Specific Gravity.

\section{INTRODUCTION}

Unilateral spinal anesthesia is becoming more popular for surgical procedures that are limited to one side of the body, especially in orthopedic lower limb surgery. Probably the most important advantage of the technique is the reduced incidence of hypotension during spinal anesthesia, in addition to facilitating faster recovery, and a good level of patient and surgeon satisfaction ${ }^{1-4}$. Unilaterality of spinal anesthesia is dependent on those factors, including baricity of the local anesthetic solution, patient position, rate of injection of local anesthetic solution into the subarachnoid space, dose-concentration-volume properties of the local anesthetic solution,

Received from Ankara Numune Training and Research Hospital, Ankara, Turkey.

1. MD; Ankara Numune Training and Research Hospital, Ankara, Turkey

Submitted on June 27, 2011.

Approved on August 01, 2011.

Corresponding author:

Dilsen Ornek, $M D$

Ankara Numune Training and Research Hospital,

Ankara-Turkey

E-mail: dilsenpinar@yahoo.com and the design of the spinal needle used when performing spinal anesthesia ${ }^{1,5-7}$.

The main goal of this prospective, randomized study was to evaluate the differences in the incidence of unilaterality of subarachnoid block between hyperbaric and hypobaric lowdose ropivacaine.

\section{MATERIAL AND METHODS}

The study included 60 patients (American Society of Anesthesia [ASA] physical status I-III) aged 18-60 years that received combined spinal epidural anesthesia (CSEA) for elective total knee arthroplasty (TKA). The study protocol was approved by the local ethic committee and written informed consent was obtained from all the patients.

Exclusionary criteria were as follows: younger than 18 years or older than 75 years, ASA risk group > III, mental disturbance, pregnancy or the possibility of pregnancy, contraindication for regional anesthesia, having participated in another clinical study within the last 30 days, previously participating in the present clinical study, and a history of local anesthetic allergy. 
Standard monitoring included heart rate, non-invasive blood pressure, respiration rate, pulse oximetry, and 3 lead electrocardiograms (Peta K800). Data were recorded at 5-minute intervals and data collected before the CSEA procedure were considered baseline.

The pain visual analog scale (VAS) was introduced to the patients and they were informed about patient-controlled epidural analgesia (PCEA). The patients were pre-hydrated with $500 \mathrm{~mL}$ of lactated Ringer solution 30 minutes prior to surgery. No premedication was administered to any of the patients.

Using a list of random numbers, the patients were assigned by an anesthetic nurse to one of the treatment groups. The patients were positioned with the surgery side down in the $15^{\circ}$ Fowler position in the hyperbaric group, and with the surgery side up in the $15^{\circ}$ Trendelenburg position in the hypobaric group. CSEA was performed in the midline at the $L_{3-4}$ lumbar interspace. The epidural space was localized with the loss of resistance technique using the Tuohy needle supplied with the combined spinal epidural set (Portex 18/27G, 16/27G, $U K)$. The spinal needle was introduced to the intrathecal space through the Tuohy needle. After observing the free flow of cerebrospinal fluid, the study solution was injected into the subarachnoid space at the rate of $1 \mathrm{~mL}$. $\mathrm{min}^{-1}$. The opening of the spinal needle was positioned to face lowermost in the hyperbaric group and uppermost in the hypobaric group. Following the removal of the spinal needle, an epidural catheter was introduced into the epidural space as the opening of the Tuohy needle facing lowermost in hyperbaric group and uppermost in the hypobaric group. In all, $3-4 \mathrm{~cm}$ of the catheter was positioned in the epidural space and the rest of the catheter was fixed to the skin.

The study solutions were prepared in $4 \mathrm{~mL}$ volumes as follows: $3 \mathrm{~mL}$ of each study solution were injected into the subarachnoid space following observation of the free flow of cerebrospinal fluid, without aspiration or barbotage. The density of the study solutions differed equally from the density of cerebrospinal fluid at room temperature. Patients in both groups were kept in the lateral position for $10 \mathrm{~min}$.

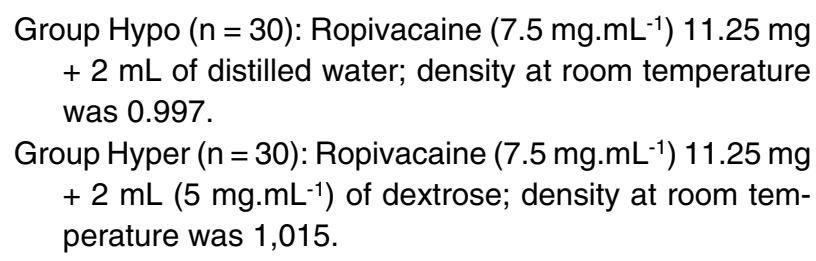

Systolic pressure, diastolic pressure, mean arterial pressure, heart rate, and oxygen saturation $\left(\mathrm{SpO}_{2}\right)$ were recorded as soon as each patient entered the surgical suite, and throughout the operation (every 5 minutes during the first 20 minutes and at the $30^{\text {th }}$ minute, every 15 minutes until the $90^{\text {th }}$ minute, and every 30 minutes until the $180^{\text {th }}$ minute). Clinically relevant hypotension (decrease in systolic arterial blood pressure $\geq 30 \%$ from baseline) was treated with intravenous infusion of $0.9 \% \mathrm{NaCl}$ solution $(250 \mathrm{~mL}$ over the course of 5 minutes); if this was not effective, $10 \mathrm{~mL}$ of ephedrine was given intravenously. Bradycardia (heart rate $<50$ beats. min $^{-1}$ ) was treated with $0.5 \mathrm{mg}$ of intravenous atropine.

The level of sensory block to reach the T10 dermatome level was determined for both the operated side and, if blocked, the non-operated side by an anesthesiologist other than the one who performed the CSEA, based on the loss of sensation to pin-prick testing in the mid-clavicular line (using a 20G hypodermic needle).

The maximum sensorial block level reached was determined and recorded for both sides based on the pin-prick test.

The level of sensorial block on both sides was recorded at zero, $5,10,15,120,150$, and 180 minutes following the administration of CSEA. The level of sensory block could not be evaluated between 15 and 120 minutes after CSEA administration because surgery was in progress and the patients were in the supine position, therefore, the level below the T10 dermatome was covered with sterile surgical drapes.

The level of motor block on both sides was recorded at zero, $5,10,15,120,150$, and 180 minutes after the CSEA, according to the modified Bromage scale. (Table I.)

The time from maximum sensory block to 2-segment regression on both sides was recorded.

The time to one level regression of maximum motor block was recorded for both the operated and the non-operated sides according to the modified Bromage scale (e.g. regression of modified Bromage scale from 3 to 2).

Successful unilateral spinal anesthesia was defined as total motor block (level 3 according to the modified Bromage scale) and loss of pain sensation based on the pin-prick test at the T10 dermatome level on the operated side, and the continuation of somatic sensation based on the pin-prick test and motor block level <2, according to the modified Bromage scale on the non-operated side. Unilateral spinal anesthesia was assessed during follow-up at 5, 10, and 15 minutes.

Patient comfort was determined according to the scale shown in Table II.

Table I - Modified Bromage Scale

\begin{tabular}{ll}
\hline 0 & No Motor Block. \\
1 & Can flex knee, move foot, but cannot raise leg. \\
2 & Can move foot only. \\
3 & Cannot move foot or knee. \\
\hline
\end{tabular}

Table II - The Patient Comfort Scale

\begin{tabular}{|c|c|}
\hline Very good & $\begin{array}{l}\text { The patient is satisfied and comfortable during the } \\
\text { CSEA procedure. }\end{array}$ \\
\hline Good & $\begin{array}{l}\text { Analgesia is sufficient, but the patient is agitated } \\
\text { during the CSEA procedure and intra-operative } \\
\text { intravenous sedative medication is needed. }\end{array}$ \\
\hline Inadequate & $\begin{array}{l}\text { Analgesia is not sufficient and analgesic } \\
\text { medication (fentanyl) is needed. }\end{array}$ \\
\hline Unsuccessful & $\begin{array}{l}\text { Analgesia is not sufficient and general anesthesia } \\
\text { is needed. }\end{array}$ \\
\hline
\end{tabular}

CSEA: combined spinal epidural anesthesia. 
Surgical comfort was evaluated according to verbal answers provided by the surgeon to the following questionnaire (0-3):

0 : It is impossible to operate under these circumstances;

1: It is possible to operate, but we are not comfortable;

2: It is possible to operate and we are comfortable, but conditions are not as good as with general anesthesia;

3: It is possible to operate and conditions are as good as with general anesthesia.

The first analgesic requirement time was the elapsed time from the administration of the intrathecal local anesthetic solution to when the patient required analgesic medication for pain relief. Postoperative analgesia was supplied by a patient-controlled analgesia (PCEA) device. The analgesic solution was prepared with $5 \mu \mathrm{g} \cdot \mathrm{mL}^{-1}$ of fentanyl citrate. The PCEA device was set for a $5 \mathrm{~mL}$ bolus dose without infusion, lock out time of $30 \mathrm{~min}$, and a $4 \mathrm{~h}$ limit of $30 \mathrm{~mL}$. The quantity of analgesic solution used by the patients was recorded in $\mathrm{mL}$. The level of demand by the patients, the amount of bolus dose supplied by the PCEA device, and maximum pain VAS scores (0-10) on the $1^{\text {st }}$ and $2^{\text {nd }}$ postoperative days were recorded.

Nausea, vomiting, bradycardia, hypotension, and decreased oxygen saturation based on pulse oximeter were recorded and consecutively treated, when present, with ondansetron hydrochloride dehydrate $4 \mathrm{mg}$ i.v., atropine $0.5 \mathrm{mg}$ i.v., intravenous fluid infusion, ephedrine $10 \mathrm{mg}$ i.v., and breathing 2 L. $\min ^{-1}$ of oxygen with a face mask.

\section{Statistical analysis}

group means and standard derivation were used to compare the measurable data; age, weight, time to reach the T10 dermatome level, motor block regression time, and operation times were analyzed with Student's t-test. Other demographic data, motor block, sensory block, and hemodynamic parameters were analyzed with the Mann-Whitney $U$ test. Inter-group data for both sides were analyzed with the Wilcoxon test. The Chi-Square test was used to analyze data obtained for gender, ASA classification, and the number of patients in which successful unilateral spinal anesthesia was achieved. The Mann-Whitney $U$ test was used for inter-group comparison of the patients that achieved a sensory block level above the T10 dermatome on the non-operated side. Remaining data were analyzed by median testing. The results were interpreted as median, percentage, or mean \pm SD. The cut-off point for statistical significance was accepted as $p<0.05$.

\section{RESULTS}

Patient demographic data and the duration of the operations are shown in Table III. There were no statistically significant differences in patient age, height and weight, or the duration of surgery between groups.

Time to reach the T10 dermatome level on the operated side was shorter in group Hyper $(612.00 \pm 163.29 \mathrm{~s})$ than in group Hypo $(763.63 \pm 208.35 s)(p<0.05)$. Patients whose sensory block dermatome level reached T10 on the non-operated side were compared between groups; the time to reach T10 was shorter in group Hyper than in group Hypo $(p<0.05)$ (Figure 1). While in the lateral position sensory block was completely unilateral in 25 patients in group Hyper (83.3\%) and in 29 patients in group Hypo $(96.6 \%)(p<0.05)$. After placing the patients in the supine position, spinal block redistributed toward the non-operated side and at the $15^{\text {th }}$ min spinal anesthesia was still unilateral in 20 patients in group Hyper (66.6\%) and in 22 patients $(73.3 \%)$ in group Hypo $(p>0.05)$. Time to 2-segment regression of the sensory block level on the operated side was shorter in group Hypo than in group Hyper $(p<0.05)$. On the non-operated side, time to 2-segment regression of the sensory block level was shorter in group Hypo than in group Hyper $(p=0.001)$. Time to reach the maximum sensory block level was similar in both groups (Figure 2).

No patients in either group required general anesthesia as a result of failed spinal anesthesia, nor did they require sedation due to discomfort. All patients reached the T10 sensory block level on the operated side.

Hemodynamic parameter changes were similar in both groups. One patient in the hyperbaric group and one patient in the hypobaric group required treatment for hypotension and both were given $250 \mathrm{~mL}$ of $\mathrm{NaCl}$ intravenously over the

Table III - Patient Demographic Data and the Duration of Surgery

\begin{tabular}{llll}
\hline & Group 1 $(\mathrm{n}=30)$ & Group 2 $(\mathrm{n}=30)$ & $\mathrm{p}$ \\
\hline Age (years) & $66.37 \pm 7.204$ & $63.67 \pm 9.026$ & 0.205 \\
${\text { Weight }(\mathrm{kg})^{*}}^{*}$ & $88.27 \pm 7.12$ & $85.27 \pm 7.38$ & 0.115 \\
Height $(\mathrm{cm})^{*}$ & $157.33 \pm 8.868$ & $157.33 \pm 6.905$ & 0.810 \\
Gender (F/M) & $24 / 6$ & $26 / 4$ & 0.488 \\
ASA (II/III) & $11 / 19$ & $12 / 18$ & 0.791 \\
Operation time $(\mathrm{min})^{*}$ & $96.60 \pm 23.992$ & $98.00 \pm 14.307$ & 0.785 \\
CSEA level & $21 / 9$ & $23 / 7$ & 0.559 \\
$\left(\mathrm{~L}_{3-4} / \mathrm{L}_{4-5}\right)$ & & & \\
\hline
\end{tabular}

CSEA: combined spinal epidural anesthesia; ${ }^{*}$ values are mean \pm SD.

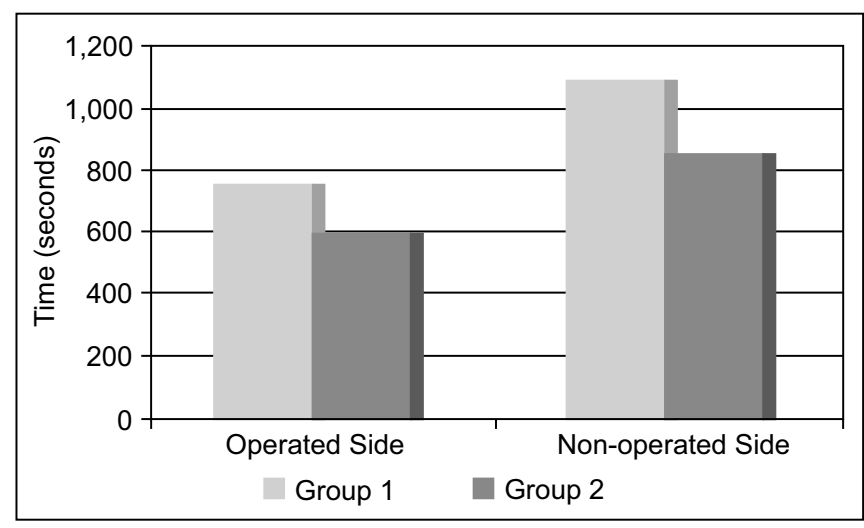

Figure 1 - Time to Reach the T10 Dermatome Level on the Operated and Non-Operated Sides. 
course of five minutes. The two patients were subsequently given $10 \mathrm{mg}$ ephedrine i.v. when this failed. None of the patients in either group needed treatment with $0.5 \mathrm{mg}$ atropine (Figure 3).

The quality of anesthesia and the patients' and surgeons' answers to the questionnaires are shown in Tables IV and V. All of the patients in the hyperbaric group and $96 \%$ of the patients in the hypobaric group indicated that they would choose the same anesthetic technique in the future for a similar ope- ration. One patient in the hypobaric group stated that he would choose general anesthesia in the future for a similar surgery, as he was disturbed by the sounds he had heard when the prosthesis was implanted.

None of the patients in either group complained about postdural puncture headache or urinary retention. First analgesic requirement time was similar in both groups. There were no complaints of backache or pain in the buttocks or legs at the $2^{\text {nd }}$ postoperative day follow-up.
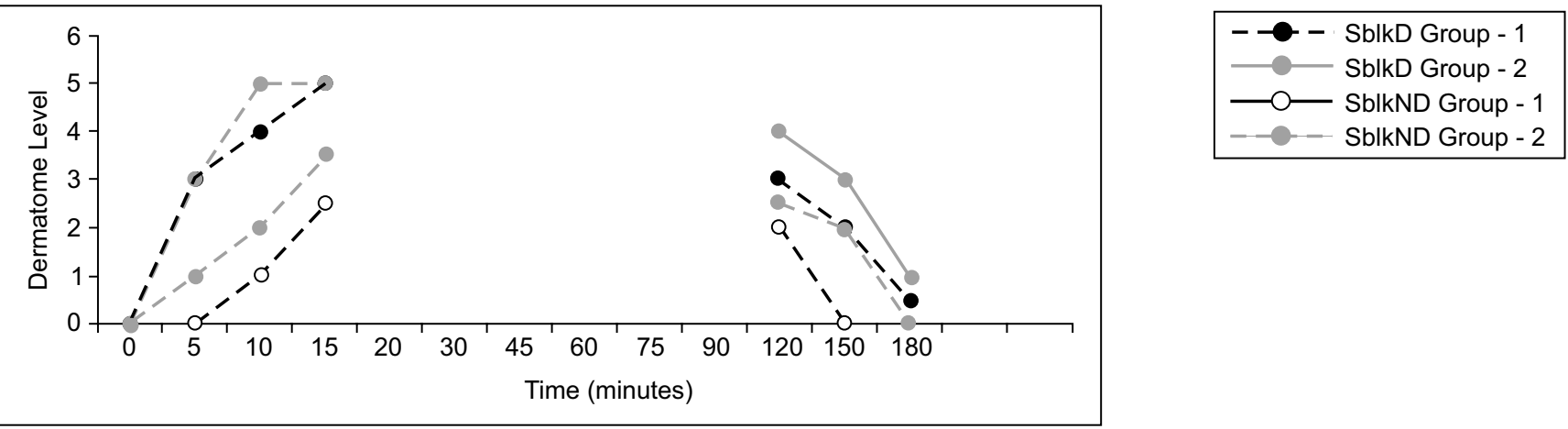

Figure 2 - Sensory Block Curves for the Operated and Non-Operated Sides.

1: $<L_{5} ; 2: L_{3-4} ; 3: L_{1-2} ; 4:$ T11-12; 5: T9-10; 6: >T8; SblkD Group 1: Sensory block dermatome level on the operated side in group 1; SblkD Group 2: Sensory block dermatome level on the operated side in group 2; SblkND Group 1: Sensory block dermatome level on the non-operated side in group 1; SblkND Group 2: Sensory block dermatome level on the non-operated side in group 2.

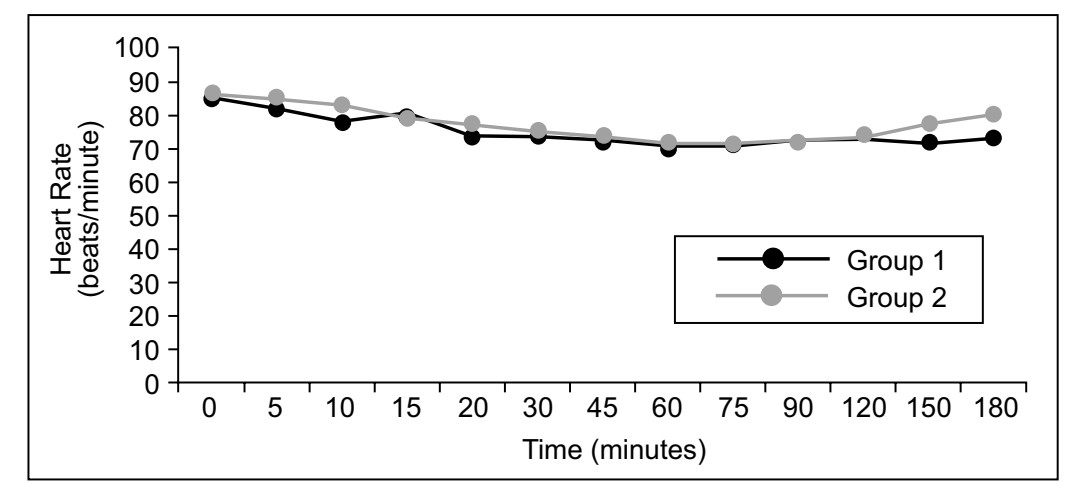

Figure 3 - Heart Rate Curves.

Table IV - Spinal Block Characteristics I

\begin{tabular}{|c|c|c|c|}
\hline & Group $1(n=30)$ & Group $2(n=30)$ & $\mathrm{p}$ \\
\hline USA $^{*}$ - lateral & $29(96.6 \%)$ & $25(83.3 \%)$ & 0.042 \\
\hline USA- supine & $22(73.3 \%)$ & $20(66.6 \%)$ & 0.048 \\
\hline Maximum sensory block level-operated & T10 (T10-T2) & T10 (T10-T6) & 0.085 \\
\hline Surgeon satisfaction & 30 & 30 & 1.0 \\
\hline Surgical comfort & 30 & 30 & 1.0 \\
\hline
\end{tabular}

*USA: unilateral spinal anesthesia; "*values are mean \pm SD. 
Table V - Spinal Block Characteristics II

\begin{tabular}{lllllll}
\hline & T10D $(\mathrm{sec})$ & T10ND $(\mathrm{sec})$ & SBRD $(\mathrm{min})$ & SBRND $(\mathrm{min})$ & MBRD $(\mathrm{min})$ & MBRND $(\mathrm{min})$ \\
\hline Group 1 & $763.63 \pm 208.35$ & $1086.67 \pm 250.0$ & $89.53 \pm 25.49$ & $57.33 \pm 26.05$ & $195.0 \pm 58.29$ & $111.0 \pm 43.97$ \\
Group 2 & $612.00 \pm 163.29$ & $850.91 \pm 189.39$ & $98.50 \pm 16.93$ & $73.00 \pm 22.19$ & $203.0 \pm 64.81$ & $113.5 \pm 44.68$ \\
$\mathrm{p}$ & 0.003 & 0.016 & 0.046 & 0.001 & 0.617 & 0.828 \\
\hline
\end{tabular}

T10D: Time to reach the T10 dermatome level on the operated side; T10ND: Time to reach the T10 dermatome level on the non-operated side; SBRD: 2-segment regression time of sensory block on the operated side; SBRND: 2-segment regression time of sensory block on the non-operated side; MBRD: Motor block regression time on the operated side; MBRND: Motor block regression time on the non-operated side.

\section{DISCUSSION}

In this randomized, prospective double-blind study $11.25 \mathrm{mg}$ of hypobaric and hyperbaric ropivacaine provided satisfactory levels of anesthesia at the operated extremity during unilateral total knee replacement surgery. The difference in specific gravity between cerebrospinal fluid and the anesthetic solution was the same in the hypobaric and hyperbaric groups. The use of anesthetic solutions with densities that were equally different from the density and specific gravity of cerebrospinal fluid provided similar distributions of nerve blockade.

The present results appear to contradict the literature ${ }^{6,8}$, but, in fact, they support it. Because the study solutions in both groups differed equally from the specific gravity and density of cerebrospinal fluid, neural blockade distribution was similar; however, according to the literature, when the nerve-blocking properties of hyperbaric and hypobaric solutions are compared, the difference in density between cerebrospinal fluid and hyperbaric solution is much greater than that of hypobaric solutions. To the best of our knowledge the present study is the first in which the baricity of hyperbaric and hypobaric ropivacaine $(11.25 \mathrm{mg})$ differed equally from the baricity of CSF at room temperature.

Casati et al. 9 reported that the use of local anesthetic solution in different concentrations affects the outcome of unilateral spinal block. Therefore, the present study used equal concentrations of ropivacaine. Kuusiniemi et al. ${ }^{10}$ compared $6 \mathrm{mg}$ of $0.5 \%$ isobaric bupivacaine and $6 \mathrm{mg}$ of $0.5 \%$ hyperbaric bupivacaine in $8 \%$ dextrose for achieving unilateral spinal anesthesia; unilaterality was $83.3 \%$ in the hyperbaric group, whereas unilateral spinal block was $37 \%$ in the isobaric group. Kaya et al. ${ }^{11}$ reported that unilateral spinal anesthesia in their hyperbaric group was $80 \%$. In the present study, unilateral spinal anesthesia in the hyperbaric group was $83.3 \%$, in accordance with the literature.

Maintaining patients in the lateral position after the administration of either hyperbaric or hypobaric local anesthetic solution intrathecally might influence the distribution of the local anesthetic solution. However, there is no consensus as to the optimal duration that patients should be kept in the lateral position, though it is greatly affected by the dose of local anesthetic solution 1,12,13. Following the administration of high doses of intrathecal local anesthetic solution, it is reported that local anesthetic migration is observed as much as one hour after intrathecal administration ${ }^{14}$. Moreover, it is reported that when small doses of local anesthetic solution are administe- red intrathecally, keeping the patient in the lateral position for 10-15 minutes limits nerve block to the operated side 5,12,15,16. Kuusunami et al. ${ }^{17}$ conducted a study in which one group was kept in the lateral position for 20 minutes and the other group for 30 minutes. Their results show that both 20 minutes and 30 minutes in the lateral position provided similar unilateral sensory block, but that motor block unilaterality was higher in the 30-minute group. Chohan et al. ${ }^{18}$ and Moellmann et al. ${ }^{19}$ reported that keeping patients in the lateral position for 10 minutes resulted in successful unilateral spinal anesthesia. Based on the literature, we kept our patients in the lateral position for 10 minutes and achieved successful unilateral spinal anesthesia in both groups. Keeping the patients in the lateral position for more than 10 minutes would prolong motor and/or sensory block recovery.

Several factors have been reported to restrict spinal block to one side. These factors include the position of the patient, the design of the spinal needle, the injection rate of the local anesthetic solution into the cerebrospinal fluid, the dose of the local anesthetic solution injected into the cerebrospinal fluid, and the baricity of the local anesthetic solution injected into the cerebrospinal fluid ${ }^{13,20}$. Reduction of the anesthetic dose is crucial to restrict spinal block to one side. In the present study, the ropivacaine dose administered intrathecally for total knee replacement surgery was the smallest ropivacaine dose ever reported. In a study reported by Kaya et al. ${ }^{11} 0.5 \%$ hyperbaric bupivacaine and $0.18 \%$ hypobaric bupivacaine were compared for achieving unilateral spinal anesthesia in lower extremity orthopedic surgery. The incidence of unilateral spinal anesthesia was $80 \%$ in the lateral position and unilaterality reduced to $68 \% 15$ minutes after patients were placed in the supine position in the hyperbaric group; whereas in the hypobaric group, the incidence of unilateral spinal anesthesia was $76 \%$ in the lateral position and $24 \%$ in the supine position. In the present study, the incidence of unilateral spinal anesthesia in the hypobaric group - when patients were in the lateral position - was $96.6 \%$ and reduced to $73.3 \%$ after they were placed in the supine position. In the hyperbaric group, the incidence of unilateral spinal anesthesia while patients were in the lateral and supine positions was $83.3 \%$ and $66.6 \%$, respectively. The unilateral spinal anesthesia incidence rate was higher in the hypobaric group in our study because the densities of the local anesthetic solutions differed equally from the density of cerebrospinal fluid at room temperature. As the baricity of local anesthetic solutions decrease with increasing temperature ${ }^{18}$, when the local anesthetic solutions were injected into the cerebrospinal fluid and thermal balance 
was achieved, the hypobaric local anesthetic solution became more hypobaric and the hyperbaric local anesthetic solution's baricity approximated that of the cerebrospinal fluid.

Stienstra et al. ${ }^{21}$ reported that small changes in the baricity of local anesthetic solution affect its distribution in the cerebrospinal fluid, regardless of the injection rate. It is yet unclear at which density and it is not possible to foresee at what rate a local anesthetic behaves hyperbaric ${ }^{18}$. Several factors affect this rate, including: the patient's, the ingredients in the local anesthetic solution, needle design, injection rate and level, volume, viscosity, protein content of the cerebrospinal fluid, and, although excluded in the present study, obstruction of the inferior vena cava in pregnant women ${ }^{22}$. These factors in the present study may have affected the hyperbaric behavior of ropivacaine.

Kuusinami et al. ${ }^{10}$ and Casati et al. ${ }^{23}$ reported that the incidence of hypotension was lower with unilateral spinal anesthesia than with conventional spinal anesthesia. Pre-hydration is one of the factors that minimize hypotension following spinal anesthesia. In the present study, all patients were prehydrated with $500 \mathrm{~mL}$ i.v. of lactated Ringer's solution. We considered hypotension as a $30 \%$ decrease from baseline mean arterial blood pressure or mean arterial blood pressure $<60 \mathrm{~mm} \mathrm{Hg}$; one patient in each group had hypotension. The patient with hypotension in group 1 was hydrated with $250 \mathrm{~mL}$ of $0.9 \% \mathrm{NaCl}$ solution i.v. and the patient with hypotension in group 2 required an additional $10 \mathrm{mg}$ of ephedrine i.v. Bradycardia was considered as $<50$ beats. $\mathrm{min}^{-1}$ in the present study and none of the patients had bradycardia.

Pencil-point needles provide a laminar flow during the injection of local anesthetic solution into the cerebrospinal fluid, which probably helps to achieve limited unilateral spinal anesthesia ${ }^{24,25}$. Another factor that helped us to achieve successful unilateral anesthesia was that the ropivacaine dose used in the present study was the smallest ropivacaine dose ever reported for total knee replacement surgery. The injection rate of the local anesthetic solution was $1 \mathrm{~mL} \cdot \mathrm{min}^{-1}$, which helped us render the block on the operated side. Patients were placed in position just before the administration of spinal anesthesia and the position helped to limit the cranial spread of unilateral spinal anesthesia.

In the present study, sensory and motor block recovery characteristics were similar to those of studies that used lowdose bupivacaine. The 2-segment regression time of sensorial block on the operated side in the hypobaric group was $89.5 \pm 26.05 \mathrm{~min}$, versus $98.53 \pm 16.93 \mathrm{~min}$ in the hyperbaric group. On the non-operated side, the 2-segment regression time of sensory block was $57.33 \pm 26.05 \mathrm{~min}$ in the hypobaric group and $73.0 \pm 22.19 \mathrm{~min}$ in the hypobaric group. The difference in 2-segment regression time of sensory block between the two groups was statistically significant, both on the operated and non-operated sides. The number of patients that achieved a sensory block level > T10 on the operated side was higher in group Hypo, which means that ropivacaine distributed within the cerebrospinal fluid over a larger area in group Hypo than in group Hyper. This helps explain the statistically significant difference in sensory block regression time. The regression time of motor block was similar in both groups: both for the operated and the non-operated sides, and all patients completely recovered from motor block within 180 minutes. Although total knee replacement surgery is not ambulatory surgery, early recovery of motor block facilitates early mobilization. None of the patients complained of clinical neurological change, postdural puncture headache, or radicular irritation during the follow-up period.

Urinary retention is a frequent side effect of spinal anesthesia, which is due to bilateral blockade of the sacral parasympathetic plexus innervating the detrusor muscle and over-hydration to treat hypotension due to spinal anesthesia. As the hemodynamic stability provided by unilateral spinal anesthesia does not necessitate over-hydration, another advantage of unilateral anesthesia is that unilateral sacral parasympathetic plexus blockage does not completely disturb the detrusor muscle function. In the present study, two patients in group Hypo and 7 patients in group Hyper complained of urinary retention and were catheterized once, micturating spontaneously 6,10 .

Postoperative analgesia was achieved using an epidural PCEA device. First analgesic requirement time was shorter in group Hypo than in group Hyper. Due to the sensory and motor block regression times being shorter in group Hypo, these patients faced postoperative pain earlier than those in group Hyper. Total analgesic solution volume used and the number of patient demands returned by the PCEA device were similar in both groups. However, is worth noting that the number of patient demands in group Hypo was much higher than in group Hyper (Figure 4). This may be an important disadvantage of the hypobaric technique, as compared to the hyperbaric technique.

In conclusion, both hyperbaric and hypobaric ropivacaine $(11.25 \mathrm{mg})$ provided adequate and dependable anesthesia for total knee replacement surgery, with a high level of patient and surgeon acceptance. The hemodynamic parameters were well preserved in both groups. Indeed, hypobaric local anesthetic solution provided a higher percentage of unilateral anesthesia with faster recovery properties, both for sensory and motor block. Therefore, even not being the concern of this study, it may be preferable in outpatient settings.

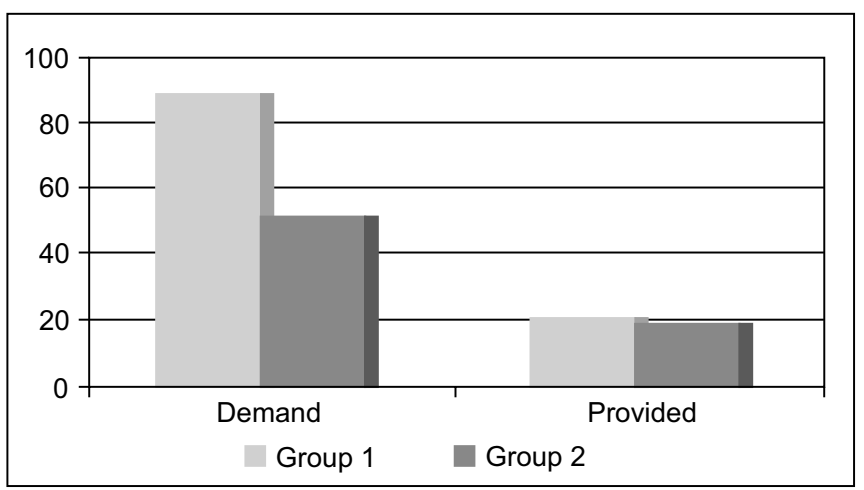

Figure 4 - Number of Demands and the Number of Demands Provided by PCEA.

*Demand: Number of analgesia demand from PCEA; ${ }^{* *}$ Provided: Number of analgesia provided by PCEA. 
5. Kuusiniemi KS, Pihlajamaki KK, Irjala JK et al. - Restricted spinal anesthesia for ambulatory surgery: a pilot study. Eur J Anaesthesiol, 1999;16:2-6.

6. Kuusiniemi KS, Pihlajam $\Delta$ ki KK, Pitkanen MT - A low dose of plain or hyperbaric bupivacaine for unilateral spinal anesthesia. Reg Anesth Pain Med, 2000;25:605-610.

7. Casati A, Fanelli G, Cappelleri GL et al. - Effects of spinal needle type on lateral distribution of $0,5 \%$ hyperbaric bupivacaine. Anesth Analg, 1998;87:355-359.

8. Casati A, Albertin A - Unilateral spinal block: Technical Issues. Em: A.Van Zundert (eds). Highlights in Regional Anaesthesia and Pain Therapy. IX. 2000 ESRA and Cyprint Ltd 2000; pp 208-211.

9. Casati A, Fanelli G, Gianluca $C$ et al. - Low dose bupivacaine for unilateral spinal anesthesia. Can J Anesth, 1998;45:850-854.

10. Kuusiniemi KS, Pihlajam $\Delta$ ki KK, Pitkanen MT, Korkeila JE - Low-dose bupivacaine: a comparison of hypobaric and near isobaric solutions for arthroscopic surgery of the knee. Anaesthesia, 1999;54:540-545.

11. Kaya M, Oguz S, Aslan K, Kadıoàlları N - A low-dose bupivacaine: $A$ comparison of hyperbaric and hypobaric solutions for unilateral spinal anesthesia. Reg Anesth and Pain Med, 2004;29(1):17-22.

12. Gentili ME, Mamelle JC, Le Foll G - Combination of low dose bupivacaine and clonidine for unilateral spinal anesthesia in arthroscopy knee surgery (Letter). Reg Anesth, 1995;20:169-170.

13. Casati A, Fanelli $G$ - Restricting spinal block to the operative side: Why Not? Reg Anesth and Pain Med, 2004;29(1):4-6.

14. Povey HMR, Jacobsen J, Westergaard-Nielsen $\mathrm{J}$ - Subarachnoid analgesia with hyperbaric $0.5 \%$ bupivacaine:effect of a $60 \mathrm{~min}$ period of sitting. Acta Anesthesiol Scand, 1989;33:295-297.

15. Esmaoàu A, Boyaci A, Ersoy O, Güler G, Talo R, Tercan E - Unilateral spinal anesthesia with hyperbaric bupivacaine. Acta Anaesthesiol Scand, 1998;42:1083-1087.

16. Pittoni G, Toffoletto F, Calcarella G, Zanette G, Giron GP - Spinal anesthesia in outpatient knee surgery: 22-gauge versus 25-Sprotte needle. Anesth Analg, 1995;81:73-79.

17. Kuusiniemi KS, Pihlajam $\Delta$ ki KK, Pitkanen MT, Korkeila JE - A lowdose hypobaric bupivacaine spinal anesthesia for knee arthroscopies. Reg Anesth, 1997;22:534-538.

18. Chohan U, Afshan G, Hoda MQ, Mahmud S - Haemodynamic effects of unilateral spinal anesthesia in high risk patients. J Pak Med Assoc, 2002;52(2):66-69.

19. Moellmann M, Kösters $C$, Cord $S$ - Unilateral spinal anesthesia.(Poster Discussion). ASRA Spring 2001; Abstract 2001S-A3.

20. Casati A, Fanelli G - Unilateral Spinal Anesthesia: State of the art. Minerva Anestesiol, 2001;67:855-862.

21. Stienstra R, Gielen M, Kroon JW, Van Poorten F - The influence of temperature and speed of injection on the distribution of a solution containing bupivacaine and methylene blue in a spinal canal model. Reg Anesth, 1990;15:6-11.

22. Lui AC, Polis TZ, Cicutti NJ - Densities of cerebrospinal fluid and spinal anesthetic solutions in surgical patients at body temperature. Can J Anaesth, 1998;45:297-303.

23. Casati A, Fanelli G, Beccaria P et al. - Block distribution and cardiovascular effects of unilateral spinal anesthesia by $0.5 \%$ hyperbaric bupivacaine. A clinical comparison with bilateral spinal block. Minerva Anestesiol, 1998;64:307-312.

\section{REFERÊNCIAS/REFERENCES}

1. Tanasichuk MA, Schultz EA, Matthews JH, Van Bergen FH - Spinal hemianalgesia: An evaluation of a method, its acceptibility, and inflence on the incidence of hypotension. Anesthesiology, 1961;22:74-85.

2. Casati A, Fanelli G, Aldegheri G et al. - Frequency of hypotension during conventional or asymmetric hyperbaric spinal block. Reg Anesth Pain Med, 1999;24:214-219.

3. Liu SS, Ware PD, Allen HW, Neal JM, Pollock JE - Dose-response characteristics of spinal bupivacaine in volunteers. Clinical implications for ambulatory anesthesia. Anesthesiology, 1996;85:729-736.

4. Fanelli G, Borghi B, Casati A, Bertini L, Montebugnoli M, Torri G - Unilateral bupivacaine spinal anesthesia for outpatient knee arthroscopy. Can J Anesth, 2000;47:746-751. 